\section{It's a match!}

Have you ever wanted intelligent intraoral technology that can help to optimise aesthetics from the first scan?

The new CS 3700 intraoral scanner from Carestream Dental makes beautiful aesthetics simple and stress free.

Imbued with innovative shade matching technology, the scanner can instantly identify the enamel shade of the area being scanned. This information is then included on the digital file which will be sent to the dental lab, making it easier than ever before to ensure that aesthetics are a perfect match!

So, what are you waiting for? Contact Carestream Dental today on 08001699692 or visit www.carestreamdental.co.uk.

\title{
Speed and accuracy - a winning combination
}

Speed and efficiency have never been so important in dentistry. As practices recover from the physical and financial disruptions of 2020 , the ability to complete dental treatment quickly - with no compromise in quality remains key.

The innovative TRIOS intraoral scanner from 3Shape, when used as part of the digital workflow from the Straumann Group, enables just this. It can scan the upper and

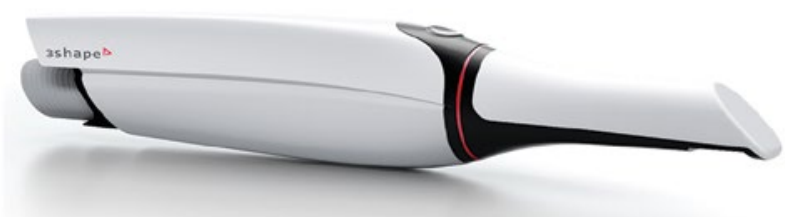

lower arches, as well as two bite impressions in just over 90 seconds. Considering that an average analogue impression takes over 11 minutes, investing in this digital workflow has the potential to significantly streamline your daily processes.

To enhance patient comfort and satisfaction, while also minimising chair time and optimising efficiency, invest in the TRIOS intraoral scanner as part of the digital workflow available through the Straumann Group.

For more information, visit at www.straumann-uk. co/cares-chairside.

\section{More support for dental hygienists and dental therapists}

Do you think it's acceptable that dental hygienists and dental therapists often have to work alone and without the support of a dental nurse?

The British Society of Dental Hygiene and Therapy (BSDHT) has recently held a survey on the issue, with thousands of respondents stating that dental nursing support should become standard practice for these clinicians.

As such, the Society is putting this issue at the forefront of its future ambitions for the profession. By raising awareness and campaigning for change the BSDHT hopes to make this extra support a reality.
To find out more, contact the BSDHT. Better yet, become a member and become part of the change!

For more information about the BSDHT, visit www.bsdht.org.uk, call 01788575050 or email enquiries@bsdht.org.uk.

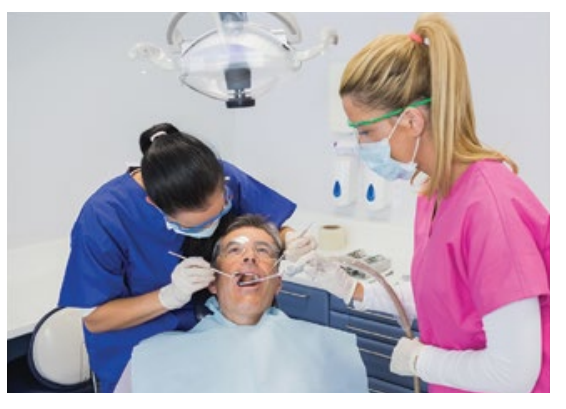

\section{The right shares at the} right time

For anyone looking to take advantage of the depressed stock market right now, investing wisely could bring financial reward in the long-run. There are several different approaches to take in order to protect your investment and maximise on the opportunities available. Whether you work on a pound-cost average, buy dividends or focus on consumer staples, the key to success will be in choosing the right shares with the right companies at the right time.

For bespoke advice and support in this and any other financial matters, the IFAs from money4dentists can help. Just give the team a call to find out how money4dentists could help you optimise your financial situation in the weeks, months and years to come.

For more information call 0845345 5060 or 0754DENTIST. Email info@ money4dentists.com or visit www. money4dentists.com.

\section{Order the products you need for every case}

IAS Academy is well known for its ethical and effective training, appliances and professional support. With the IAS Shop, ordering the products and materials you need for every case is now even easier.

The IAS Shop provides all kinds of dental and orthodontic tools and products, including wires, bonding agents and brackets, as well as clinical manuals and helpful guides. They can be purchased as standalone items or added to patient boxes. There are also starter packs for all dentists who are new to the systems and free marketing materials to help professionals promote their services efficiently.

With everything in one, easy-to-use and convenient location, the online IAS Shop makes delivering quality orthodontic treatment to patients simpler. Have a look around today!

For more information about IAS Laboratory products, email enquiries@ iasortho.com or call 01932336470 (Press 6). 